\title{
PENERAPAN DAN KEMUTAKHIRAN SNI 09-4663-1998 TENTANG KURSI RODA OLEH PEMANGKU KEPENTINGAN
}

\section{Implementation and Update of SNI 09-4663-1998 on Wheelchair by Stakeholder}

\author{
Meilinda Ayundyahrini ${ }^{1}$, Suprapto ${ }^{1}$, Putty Anggraeni $^{1}$, Fahrina Fahma² dan Wahyudi Soetopo ${ }^{2}$ \\ ${ }^{1}$ Pusat Riset dan Pengembangan Sumber Daya Manusia, Badan Standardisasi Nasional Gedung 1 BPPT Lantai \\ 12, JI. M.H.Thamrin no 8, Kebon Sirih, Jakarta Pusat 10340, DKI Jakarta, Indonesia \\ ${ }^{2}$ Teknik Industri, Universitas Sebelas Maret, JI. Ir. Sutami No.36A, Jebres, \\ Kota Surakarta, Jawa Tengah \\ e-mail: meilinda.ayundyahrini@bsn.go.id
}

Diterima: 30 Januari 2019, Direvisi: 13 Maret 2019, Disetujui: 29 Maret 2019

\begin{abstract}
Abstrak
Pemerintah wajib menjamin ketersediaan fasilitas pelayanan kesehatan dan memfasilitasi penyandang disabilitas untuk dapat tetap hidup mandiri dan produktif secara sosial dan ekonomis seperti yang tertuang dalam UndangUndang Nomor 36 Tahun 2009 tentang Kesehatan. Pasal 42, ayat (3) Undang-Undang tersebut mengamanatkan bahwa teknologi dan produk teknologi kesehatan harus memenuhi standar. Indonesia sendiri telah memiliki 189 SNI terkait alat kesehatan, namun tidak ada yang diberlakukan secara wajib. Salah satunya SNI 09-4663-1998 tentang kursi roda. Masalahnya adalah setelah 20 tahun SNI 09-4663-1998 ditetapkan belum ada produk kursi roda bertanda SNI di pasar. Penelitian ini bertujuan untuk mengetahui penerapan SNI 09-4663-1998 tentang kursi roda oleh pemangku kepentingan dan kemutakhiran standar dalam rangka persiapan kaji ulang standar 094663-1998. Penelitian menggunakan metode kualitatif dan kuantitatif (mix method). Pengumpulan data primer dilakukan secara proporsional sampling dengan instrumen kuesioner dan Focus Group Discussion. Responden penelitian ini adalah 6 (enam) produsen kursi roda, 3 (tiga) pakar, dan 6 (enam) konsumen. Hasil penelitian menunjukkan bahwa SNI 09-4663-1998 telah diketahui oleh 66,67\% responden namun hanya 33,33\% responden yang menerapkan SNI 09-4663-1998. Sedangkan 66,67\% menggunakan standar lain, yaitu ISO 7176 series. Hal ini diidentifikasi selain karena 33,33\% produsen melakukan ekspor, regulator belum menjadikan SNI 09-46631998 sebagai dasar penilaian dan persyaratan izin edar produk kursi roda. SNI 09-4663-1998 juga dianggap tidak mengikuti perkembangan teknologi dan standar internasional sehingga diperlukan revisi yang minimal mencakup parameter keamanan, kekuatan dan ketahanan. Hasil penelitian ini bermanfaat sebagai masukan untuk melakukan revisi terhadap SNI 09-4663-1998.
\end{abstract}

Kata kunci: ISO 7176 series, kursi roda, Standar Nasional Indonesia

\section{Abstract}

The government is obliged to guarantee the availability of health service facilities for persons with disabilities to be able to live independently and productively socially and economically through Law Number 36 Year 2009 concerning Health. This Law mandates that technology and health technology products shall meet the Standards. The SNI 09-4663-1998 is an Indonesian Standard about wheelchair, but after 20 years this standard has been established there is no whellchair product with SNI mark in the market. This research aims to know the application of SNI 09-4663-1998 by stakeholders and up to date of standard. By Using qualitative and quantitative methods, primary data collection is done by proportional sampling with questionnaire instruments and Focus Group Discussion. Respondents were six wheelchair producers, three experts, and six consumers. The results showed that SNI 09-4663-1998 was recognized by $66.67 \%$ of respondents but only $33.33 \%$ respondents applied. While $66.67 \%$ use other standards, namely ISO 7176 series. This was identified that $33.33 \%$ of producers exported, the regulator had not made SNI 09-4663-1998 as the basis for the assessment and requirements for the circulation of wheelchair products. Besides, SNI 09-4663-1998 is considered not follow developments in technology and international standards, thus a revision is needed by accommodating some parameters including safety, strength and durability. This research is useful as input for the revision of SNI 09-4663-1998.

Keyword: Indonesia National Standard, ISO 7176 series, wheelchair

\section{PENDAHULUAN}

Berdasarkan angka yang ditetapkan oleh WHO (World Health Organization) pada tahun 2012 terdapat $15 \%$ penyandang disabilitas di Indonesia (mencapai 36.841.956 dari populasi keseluruhan penduduk 245 juta) (Thohari, 2014). Hasil Susenas tahun 2012 menunjukkan bahwa penderita disabilitas fungsional tertinggi adalah kesulitan melihat, berjalan atau naik tangga, dan mendengar. Tingginya kesulitan berjalan selaras dengan tingginya penggunaan kursi roda sebagai 
salah satu alat pembantu mobilitas. Selain digunakan oleh penyandang disabilitas, kursi roda juga digunakan oleh masyarakat yang kurang sehat, usia manula dan masyarakat yang kehilangan fungsi bagian tubuh dari tungkai kaki sehingga kaki tidak dapat menahan beban badan.

Pemerintah Indonesia menunjukkan perhatiannya terhadap hak-hak penyandang disabilitas dengan menandatangani Konvensi Persatuan Bangsa-Bangsa (PBB) tentang hakhak penyandang disabilitas. Komitmen tersebut dilanjutkan dengan diberlakukannya UndangUndang Nomor 36 Tahun 2009 tentang Kesehatan yang menyatakan bahwa upaya pemeliharaan kesehatan bagi penyandang cacat harus ditujukan untuk menjaga agar penyandang cacat tetap dapat hidup sehat dan produktif secara sosial, ekonomis, dan bermartabat. Berdasarkan undang-undang tersebut, Pemerintah dalam hal ini mempunyai kewajiban untuk menjamin ketersediaan fasilitas pelayanan kesehatan dan memfasilitasi penyandang cacat sehingga tujuan dari upaya pemeliharaan kesehatan bagi penyandang cacat dapat tercapai.

Undang-Undang Nomor 36 Tahun 2009 Pasal 42, ayat (3) terkait Teknologi dan Produk Teknologi Kesehatan mengamanatkan bahwa teknologi dan produk teknologi kesehatan harus memenuhi standar yang ditetapkan dalam peraturan perundang-undangan. Adapun sanksi yang dapat menjerat pelaku apabila sengaja memproduksi atau mengedarkan alat kesehatan yang tidak memenuhi standar dan/atau syarat keamanan, khasiat atau kemanfaatan, dan mutu tertuang pada Pasal 196.

Indonesia sendiri telah memiliki 189 SNI terkait alat kesehatan, namun tidak ada yang diberlakukan secara wajib, dengan alasan belum tersedianya laboratorium penguji dan lembaga sertifikasi produk yang mendukung penerapan SNI alat kesehatan. Pemberlakuan secara sukarela ini disebabkan Kementerian Kesehatan belum menjadikan SNI sebagai persyaratan dalam mendapatkan izin edar. Salah satunya SNI 09-4663-1998 tentang kursi roda yang telah berusia 20 tahun tanpa ada pembaruan, karena masih sangat sedikit yang menerapkan dan belum ada usulan revisi dari stakeholder. Standar tersebut mencakup acuan, definisi, bahan, tipe, syarat mutu, cara pengambilan contoh, cara uji, syarat lulus uji, syarat penandaan dan pengemasan kursi roda. SNI 09-4663-1998 sendiri telah mengacu International Organization for Standardization (ISO), yaitu ISO 7176-1 dan 7176-5 yang merupakan standar internasional kursi roda dan Japanese Industrial Standars (JIS) yaitu JIS G 3141 SPCC (Steel Plate Cold Rolled Coiled) untuk kesesuaian bahan kursi roda. Masalahnya adalah setelah 20 tahun SNI 094663-1998 ditetapkan belum ada produk kursi roda bertanda SNI di pasar.
Penelitian tentang kursi roda dan penggunanya di Indonesia telah banyak dilakukan. Tarsidi (2011) salah satu yang mengidentifikasi kesulitan pengguna kursi roda dalam hal arsitektur dan infrastruktur di Indonesia. Adapun, standar terkait kursi roda telah menjadi perhatian penting bagi para peneliti, perkembangan inovasi kursi roda dengan acuan ISO 7176 series, utamanya dalam hal dimensi kursi roda untuk kenyamanan pengguna (Batan, 2006; Soewardi, Ajie \& Jalal, 2015). Sedikit berbeda, Ayu Anggit Pradita (2018) merekomendasikan revisi ISO 7176-5 tentang dimensi kursi roda. Sayangnya, hingga saat ini belum ada penelitian yang menyinggung secara langsung SNI 09-4663-1998 terkait kursi roda.

Penelitian ini bertujuan untuk mengetahui penerapan SNI 09-4663-1998 tentang kursi roda oleh pemangku kepentingan dan kemutakhiran standar tersebut. Sehingga hasil dari penelitian ini dapat bermanfaat sebagai masukan dalam upaya melakukan kaji ulang SNI 09-4663-1998 tentang kursi roda yang berlaku di Indonesia.

\section{TINJAUAN PUSTAKA}

\subsection{Kursi Roda Manual}

Menurut Batan (2006) kursi roda (wheelchair) adalah salah satu alat bantu bagi penyandang cacat kaki untuk dapat berpindah dari satu tempat ke tempat lain, baik di tempat datar maupun dari tempat rendah ke tempat yang lebih tinggi (tempat menanjak). Sering juga dimaksudkan, bahwa kursi roda digunakan untuk meningkatkan kemampuan mobilitas bagi orang yang memiliki kekurangan seperti: orang yang cacat fisik (khususnya penyandang cacat kaki), pasien rumah sakit yang tidak diperbolehkan untuk melakukan banyak aktivitas fisik, orang tua (manula), dan orang yang memiliki resiko tinggi untuk terluka, bila berjalan sendiri (Ady, 2011).

Secara umum kursi roda dibagi menjadi 2 (dua) jenis, yaitu kursi roda manual (conventional wheelchair) dan kursi roda berpenggerak motor atau elektrik (motor powered wheelchair) (Batan, 2006). Kursi roda manual digerakkan dengan cara didorong oleh orang lain ataupun digerakan sendiri oleh penggunanya dengan menggunakan tangan. Kursi roda elektrik dilengkapi dengan sistem pengendali elektrik untuk memudahkan mobilitas penggunanya, sehingga mereka tidak perlu mengendalikan kursi roda secara manual dengan menggerakkan roda mengunakan tangan.

Umumnya kursi roda manual terdiri dari kursi tradisional dengan 2 (dua) set roda terletak disampingnya. Satu set roda besar terletak di belakang sedangkan satu set lainnya terdiri dari roda kecil dengan diameter 5 atau 8 inchi. Desain 
tersebut membuat roda stabil dan mudah untuk bergerak maju maupun mundur (Ady, 2011).

\subsection{SNI 09-4663-1998 tentang Kursi Roda}

Tipe kursi roda yang diatur dalam SNI 09-46631998 adalah 3 (tiga) tipe, yaitu: a) tipe kursi roda dorong (push chair type), b) tipe kursi roda pelek (handrim wheel chair type), dan c) Tipe kursi roda kendali tangan tak langsung (indirect hand driver wheel chair type). Berhubungan dengan syarat mutu, SNI 09-4663-1998 mengkategorikan dalam 7 (tujuh) parameter:

1. Sifat Tampak

2. Konstruksi

3. Tahan Jatuh

4. Beban Statis

5. Pelapisan luar dudukan dan sandaran

6. Pelapisan Logam

7. Ketahanan dan Kelancaran Roda

(Badan Standardisasi Nasional, 1998)

\section{METODE PENELITIAN}

Penelitian ini menggunakan metode deskriptif kualitatif dan kuantitatif. Metode kuantitatif digunakan untuk mengidentifikasi penilaian parameter pada SNI 09-4663-1998. Sedangkan metode deskriptif kualitatif dilakukan untuk mendeskripsikan apa-apa yang saat ini terjadi. Didalamnya terdapat upaya mendeskripsikan, mencatat, analisis dan menginterpretasikan kondisi yang terjadi atau ada saat ini.

Pengumpulan data primer dilakukan secara proportional sampling dengan instrumen kuesioner dan Focus Group Discussion. Kuesioner memuat pertanyaan tentang demografi perusahaan, kemutakhiran parameter SNI 094663-1998, dan hambatan dalam penerapan standar tersebut. Data yang digunakan adalah populasi produsen kursi roda dari Kementerian Kesehatan yang berjumlah 10 (sepuluh) perusahaan dengan 6 (enam) produsen sebagai responden. Selain produsen, responden juga terdiri dari 3 (tiga) pakar, dan 6 (enam) konsumen. Lokus penelitian berada di Palembang, Jakarta, Tangerang, Depok, Yogyakarta, Surakarta, dan Semarang. Lokus tersebut dipilih karena merupakan kota produsen kursi roda, perwakilan rumah sakit dengan skala menengah dan besar, serta tempat rehabilitasi penyandang disabilitas.

Penelitian ini biasanya disebut penelitian deduktif, rasional-empiris, dimana kesimpulan diambil dari data-data lapangan dan hasil dari survei. Dari survei yang akan digambarkan dalam angka, maka penelitian kemudian akan dijadikan acuan untuk menggambarkan kecenderungan yang terjadi dalam realitas dan juga menjadi dasar untuk menafsirkannya. Dari hasil temuan dilapangan peneliti akan menyajikannya dalam bentuk angka, gambar dan grafik yang akan mengekpresikan realitas yang ada (Arikunto, 2010).

\section{HASIL DAN PEMBAHASAN}

\subsection{Penerapan SNI 09-4663-1998}

SNI 09-4664-1998 ditetapkan pada tahun 1998. Hingga saat ini berarti sudah 20 tahun belum pernah direvisi. Hasil isian kuesioner dari perusahaan sebagai pemeran utama penerapan standar menunjukkan SNI 09-4663-1998 telah diketahui oleh $66,67 \%$ responden namun hanya $33,33 \%$ responden yang menerapkan SNI 094663-1998. Sedangkan $66,67 \%$ menggunakan standar lain, yaitu ISO 7176 series. Hal ini disebabkan antara lain karena SNI belum diwajibkan, produsen yang mengekspor ke negara lain menggunakan standar internasional ISO 7176 series.

ISO 7176 series banyak digunakan di negara Eropa dan Amerika, sedangkan Indonesia yang didominasi oleh produk impor dari Cina dan beberapa produsen dalam negeri belum memenuhi ISO 7176-5:2008 (Pradita, 2018). Sedangkan SNI 09-4663-1998 tidak diterapkan karena dianggap belum dapat menjawab permintaan pasar saat ini (Pratiwi, 2018).

Belum ada data yang menyebutkan besar konsumsi kursi roda di Indonesia namun diperoleh masukan dari 1 (satu) produsen utama kursi roda bahwa Indonesia mengkonsumsi 10.000-15.000 produk/bulan. Konsumsi tersebut untuk memenuhi kebutuhan penyandang disabilitas dan orang sakit. Dari hasil pengambilan data primer didapatkan bahwa produksi kursi roda oleh perusahaan lokal sangat kecil, yaitu hanya $0,42 \%$ yang berarti sebesar $99,58 \%$ dipasok dari kursi roda impor, meskipun semua responden mengaku memiliki produk yang berdaya saing. Kursi roda yang beredar di pasar komersial Indonesia didominasi oleh produk import dari China dengan harga yang terjangkau (Pradita et al., 2018).

Harga kursi roda yang menggunakan standar 7176 series berkisar antara Rp 2.400.000,- sampai Rp 3.200.000,-. Sedangkan kursi roda impor dipatok dengan harga yang cukup terjangkau yaitu sekitar $\mathrm{Rp}$ 950.000,sampai $\operatorname{Rp} 1.350 .000$,-.Sedangkan salah satu kursi roda dalam negeri yang berbahan dasar stainless steel dan steel dengan kisaran harga Rp 2.400.000,- sampai Rp 2.600.000,- (Pradita et al., 2018). 


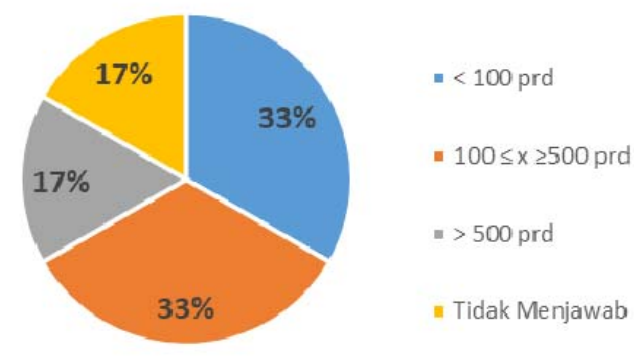

Gambar 1 Produksi kursi roda per tahun.

Sumber: Data Olah (2018).

Produksi kursi roda per tahun oleh perusahaan dalam negeri terdapat pada Gambar 1. Selain itu, $33,33 \%$ responden telah berhasil melakukan ekspor ke negara lain, $16,67 \%$ melakukan impor komponen kursi roda, dan $50 \%$ tidak menjawab apakah melakukan transaksi dengan negara lain.

Produsen kursi roda beranggapan memiliki produk yang berdaya saing dan mengaku menguji kelayakan produk sebelum dipasarkan $(83,33 \%)$ namun hanya 1 (satu) produsen $(16,67 \%)$ yang mengujikan produknya di laboratorium berakreditasi KAN, sisanya menggunakan laboratorium pabrik.

\subsection{Analisis gap SNI 09-4663-1998 dan ISO 7176-series}

Dalam penyusunan standardisasi diharapkan dapat harmonis dengan standar internasional sehingga dalam pengembangannya perlu memperhatikan aturan, regulasi dan standar internasional. Selain itu, perbandingan standar digunakan untuk mengetahui acuan atau rujukan dalam penyusunan standar tersebut. Standar internasional kursi roda tercakup dalam ISO, yaitu pada ISO 7176 series yang terdapat 16 (enam belas) ISO dengan lingkup kursi roda, baik kursi roda manual maupun kursi roda elektrik. Selain ISO 7176 series, standar yang berlaku di Indonesia adalah SNI 09-4663-1998 tentang Kursi Roda.

Berdasarkan pengolahan data primer stakeholder masih sangat setuju dengan parameter SNI 09-4663-1998. Hal ini ditunjukkan dengan nilai $>4$ (dengan skala likert 1-5) seperti pada Tabel 1. Namun apabila dibandingkan dengan ISO 7176-series, SNI 09-4663-1998 dianggap kurang spesifik. Pratiwi (2018) menyampaikan bahwa SNI 09-4663-1998 tidak memenuhi kepastian kualitas, kesesuaian dengan pengguna, keamanan penggunaan, dan produktivitas penggunaan jangka panjang.

Tabel 1 Penilaian stakeholder tentang SNI 09-4663-1998.

\begin{tabular}{|c|c|c|}
\hline No & SNI 09-4663-1998 & Rata-rata \\
\hline \multirow[t]{3}{*}{1} & Sifat Tampak & \\
\hline & Kursi roda yang telah dirakit tidak boleh terlihat adanya cacat akibat proses perakitan & 4.333 \\
\hline & $\begin{array}{l}\text { Komponen-komponen kursi roda seperti kerangka, dudukan, sandaran dan kursi roda } \\
\text { tidak boleh terlihat adanya cacat-cacat akibat proses pembuatan (contoh:pemotongan, } \\
\text { penekukan, dan pengelasan) }\end{array}$ & 4.267 \\
\hline \multirow[t]{6}{*}{2} & Konstruksi & \\
\hline & $\begin{array}{l}\text { Sambungan dengan pengelasan, pengelingan pada kerangka harus dilakukan menurut } \\
\text { norma pengelasan dan pengelingan yang berlaku }\end{array}$ & 4.333 \\
\hline & Kursi roda pada keadaan terbuka harus menempel pada lantai & 4.133 \\
\hline & $\begin{array}{l}\text { Posisi kursi roda minimal tegak lurus dari lantai dan tidak boleh miring kearah sudut } \\
\text { negatif (keluar) }\end{array}$ & 4.067 \\
\hline & $\begin{array}{l}\text { Jarak antara sisi kaki samping kanan harus sama dengan sisi samping kiri dan jarak } \\
\text { antara kaki-kaki bagian muka dan belakang harus sama/sejajar }\end{array}$ & 4.200 \\
\hline & $\begin{array}{l}\text { Kursi harus mudah dibuka dari lipatannya dan ditutup kembali, khusus untuk kursi roda } \\
\text { yang dilipat }\end{array}$ & 4.467 \\
\hline \multirow[t]{2}{*}{3} & Tahan Jatuh & \\
\hline & $\begin{array}{l}\text { Kursi roda dalam keadaan terlipat atau tidak, tidak mengalami perubahan bentuk/ } \\
\text { kerusakan konstruksi setelah mengalami uji kejatuhan }\end{array}$ & 4.267 \\
\hline \multirow[t]{2}{*}{4} & Beban Statis & \\
\hline & $\begin{array}{l}\text { Kursi roda dalam keadaan terbuka tidak mengalami kerusakan/ perubahan bentuk dan } \\
\text { ukuran akibat pembebanan statis seberat } 1,5 \text { kali kapasitas kursi roda }\end{array}$ & 4.200 \\
\hline \multirow[t]{2}{*}{5} & Pelapisan luar dudukan dan sandaran & \\
\hline & $\begin{array}{l}\text { Bahan baku pelapisan luar dudukan dan sandaran mempunyai daya tarik minimal } 11 \\
\mathrm{kgf} / \mathrm{mm}^{2} \text { atau bahan lainnya yang mempunyai kekuatan setara }\end{array}$ & 4.200 \\
\hline
\end{tabular}




\begin{tabular}{lll}
\hline \hline No & \multicolumn{1}{c}{ SNI 09-4663-1998 } \\
\hline & $\begin{array}{l}\text { Bahan baku pelapisan logam harus menurut norma yang berlaku dengan ketebalan } \\
\text { minimal 10mm untuk lapisan bahan logam dan minimal 20mm untuk ketebalan lapisan } \\
\text { bahan non logam }\end{array}$ \\
\hline 7 & Ketahanan dan Kelancaran Roda \\
& $\begin{array}{l}\text { Kursi roda tidak boleh terjadi deformasi dan gangguan kelancaran gerakan roda jika } \\
\text { diberi beban sebesar 1,2 kali kapasitas kursi roda }\end{array}$ \\
\hline
\end{tabular}

Sumber: Data Olah (2018).

Berbagai referensi pengguna kursi roda membutuhkan produk dengan harga terjangkau, memudahkan aksesbilitas, tahan lama, aman, nilai pasar, user friendly (Sahl, Sufa, \& Nursanti, 2014), menggunakan asisten yang artinya kursi roda perlu dilengkapi dengan push handle (Frost et al., 2015), serta ketahanan produk (Gebrosky et al., 2013).
Analisis gap SNI 09-4663-1998 dan ISO 7176 series yang berkaitan dengan kursi roda manual terdapat pada Tabel 2. Terdapat 9 (sembilan) standar ISO yang berkaitan dengan kursi roda manual. Parameter yang digunakan pada Tabel 2 didapatkan dari berbagai referensi dalam penelitian Pratiwi (2018).

Tabel 2 Analisis gap SNI 09-4663-1998 dengan ISO 7176 series dari berbagai referensi.

\begin{tabular}{|c|c|c|c|c|c|}
\hline Dimensi & Parameter & Sub Parameter & $\begin{array}{l}\text { ISO } 7176 \\
\text { series }\end{array}$ & $\begin{array}{l}\text { SNI 09- } \\
4663-1998\end{array}$ & Keterangan \\
\hline \multirow{8}{*}{$\begin{array}{l}\text { Dimensi } \\
\text { Performa } \\
\text { Fungsional }\end{array}$} & \multirow[b]{2}{*}{ Stabilitas } & Stabilitas Statis & $\mathrm{V}$ & $\mathrm{X}$ & \\
\hline & & Stabilitas Dinamis & V & $x$ & $\begin{array}{l}\text { Untuk Kursi roda } \\
\text { elektrik (ISO, 2017) }\end{array}$ \\
\hline & \multirow{2}{*}{$\begin{array}{l}\text { Perpindahan } \\
\text { Kursi Roda }\end{array}$} & $\begin{array}{l}\text { Kemudahan berpindah } \\
\text { dari dan ke kursi roda }\end{array}$ & $X$ & $\mathrm{X}$ & \\
\hline & & $\begin{array}{l}\text { Kemudahan mengangkut } \\
\text { kursi roda }\end{array}$ & $x$ & $x$ & \\
\hline & \multirow[b]{2}{*}{$\begin{array}{l}\text { Kemampuan } \\
\text { Manuver }\end{array}$} & $\begin{array}{l}\text { Manuver di sekitar } \\
\text { rintangan (ruang terbatas) }\end{array}$ & V & $\mathrm{X}$ & \\
\hline & & $\begin{array}{l}\text { Manuver melewati } \\
\text { rintangan }\end{array}$ & V & $x$ & $\begin{array}{l}\text { Rintangan berupa } \\
\text { tangga untuk kursi } \\
\text { roda elektrik (ISO, } \\
2015 \text { ) }\end{array}$ \\
\hline & \multirow{2}{*}{$\begin{array}{l}\text { Fungsi } \\
\text { Tambahan }\end{array}$} & $\begin{array}{l}\text { Efisiensi Energi (energi } \\
\text { kecil untuk menggerakkan } \\
\text { kursi roda) }\end{array}$ & V & $\mathrm{X}$ & $\begin{array}{l}\text { Untuk Kursi roda } \\
\text { elektrik (ISO, 2008) }\end{array}$ \\
\hline & & $\begin{array}{l}\text { Kemudahan memperbaiki/ } \\
\text { memperoleh komponen }\end{array}$ & V & $\mathrm{X}$ & \\
\hline \multirow{18}{*}{$\begin{array}{l}\text { Dimensi } \\
\text { Dudukan } \\
\text { dan } \\
\text { Dukungan } \\
\text { Postural }\end{array}$} & \multirow{11}{*}{$\begin{array}{l}\text { Dimensi } \\
\text { Kursi Roda }\end{array}$} & Panjang kursi roda & $\mathrm{V}$ & $\mathrm{X}$ & \\
\hline & & Lebar kursi roda & V & $\mathrm{X}$ & \\
\hline & & Tinggi total kursi roda & V & $\mathrm{X}$ & \\
\hline & & Tinggi kursi & $\mathrm{V}$ & $\mathrm{X}$ & \\
\hline & & Lebar tempat duduk & $\mathrm{V}$ & $\mathrm{X}$ & \\
\hline & & $\begin{array}{l}\text { Tinggi tempat duduk dari } \\
\text { tanah }\end{array}$ & V & $\mathrm{X}$ & \\
\hline & & $\begin{array}{l}\text { Tinggi sandaran tangan } \\
\text { dari tempat duduk }\end{array}$ & V & $X$ & \\
\hline & & Panjang tempat duduk & $\mathrm{V}$ & $\mathrm{X}$ & \\
\hline & & Tinggi sandaran & $\mathrm{V}$ & $\mathrm{X}$ & \\
\hline & & Berat maksimal kursi & $\mathrm{V}$ & $\mathrm{X}$ & \\
\hline & & $\begin{array}{l}\text { Menyesuaikan } \\
\text { antropometri masyarakat } \\
\text { Indonesia }\end{array}$ & $\mathrm{X}$ & $\mathrm{X}$ & \\
\hline & \multirow{4}{*}{$\begin{array}{l}\text { Dudukan } \\
\text { dan } \\
\text { Dukungan } \\
\text { Postural }\end{array}$} & Tipe Kursi & $\mathrm{X}$ & $\mathrm{V}$ & \\
\hline & & Bantalan kursi & $\mathrm{V}$ & $\mathrm{X}$ & \\
\hline & & Bahan kursi & $\mathrm{X}$ & $\mathrm{X}$ & \\
\hline & & Bahan bantalan kursi & $\mathrm{V}$ & $\mathrm{X}$ & \\
\hline & \multirow{3}{*}{$\begin{array}{l}\text { Adjustable } \\
\text { and } \\
\text { Ergonomic } \\
\text { Factor }\end{array}$} & $\begin{array}{l}\text { Sandaran punggung } \\
\text { (backrest) }\end{array}$ & V & $\mathrm{X}$ & \\
\hline & & Pijakan kaki (pijakan kaki) & $\mathrm{V}$ & $\mathrm{X}$ & \\
\hline & & $\begin{array}{l}\text { Sandaran tangan } \\
\text { (armrest) }\end{array}$ & V & $\mathrm{X}$ & \\
\hline
\end{tabular}




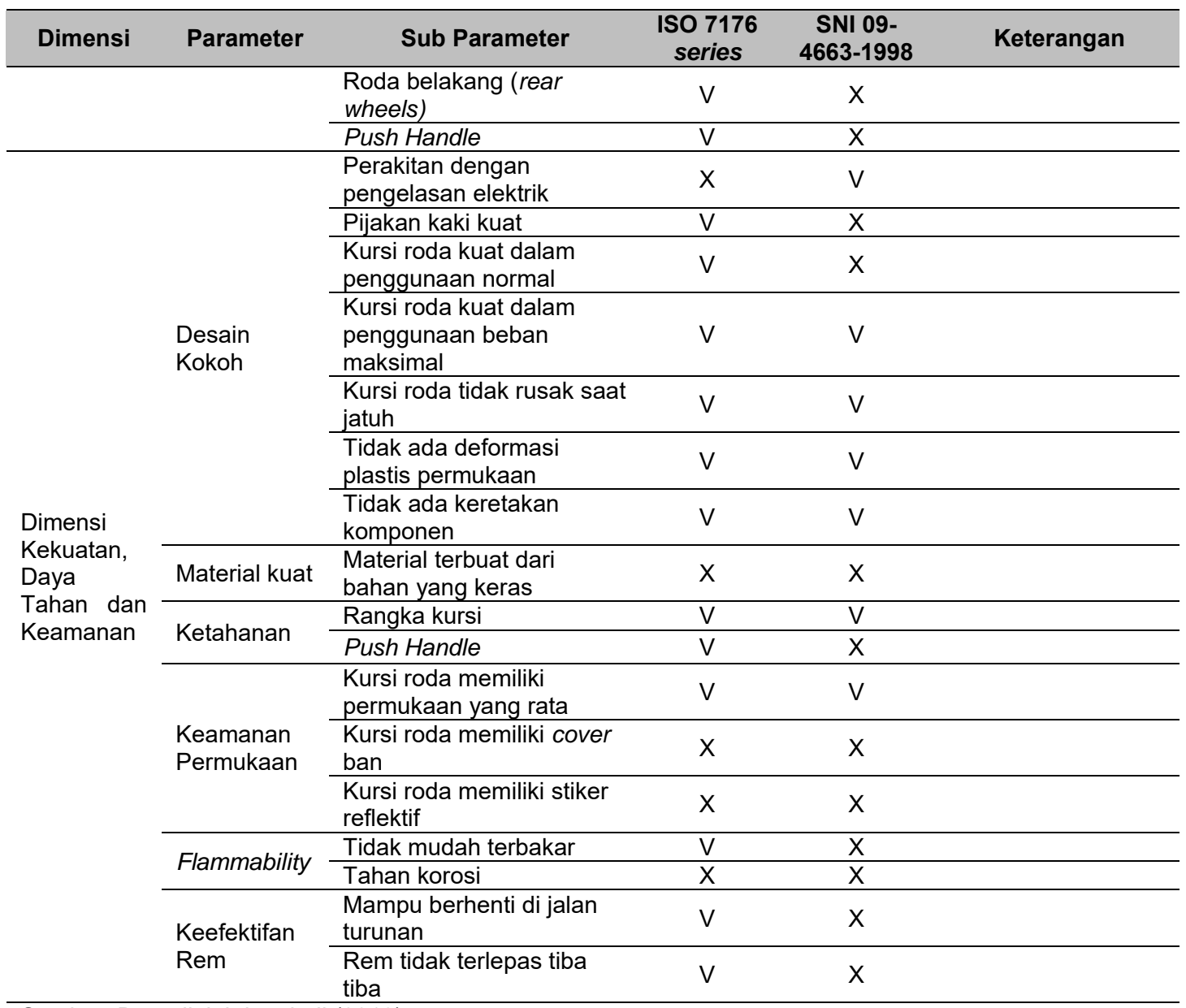

Sumber: Data diolah kembali (2018)

Keterangan: $\mathrm{X}=$ Tidak Ada

$$
\mathrm{V}=\mathrm{Ada}
$$

Permasalahan yang didapatkan dari survei lapangan, Focus Group Discussion dan analisis gap antara lain:

1. Judul SNI yang tidak spesifik, mengingat saat ini perkembangan teknologi kursi roda cukup pesat. Sedangkan ruang lingkup adalah kursi roda manual.

2. SNI 09-4663-1998 banyak mencakup parameter kekuatan. Namun dalam hal keamanan berupa stabilitas statis dan keefektifan rem belum tercakup pada standar kursi roda. Stabilitas statis digunakan pada saat kursi roda dalam keadaan diam, menaiki atau menuruni permukaan miring (ISO, 2014). Sedangkan rem digunakan untuk parkir dan mendukung kestabilan.

3. Selain itu ditemukan dari hasil pengujian laboratorium produk impor banyak mengalami kegagalan patah pada as atau pusat roda. Sehingga diperlukan pengujian fatigue untuk menguji kelayakan produk dan belum diakomodir pada SNI 09-4663-1998. Selain itu patah pada as atau pusat roda sangat bergantung pada kualitas penyambungan rangka dan kastor (Mhatre, Ott, \& Pearlman, 2017). Pengujian fatigue terdapat pada ISO 7176 (2014). Pengujian menggunakan multi drum test dengan uji sebanyak 200.000 revolutions.

Kastor juga mempengaruhi kemampuan manuver kursi roda. Spesifikasi kastor untuk kursi roda belum diatur pada SNI 09-4663-1998. Indonesia telah memiliki SNI ISO 22882:2011 tentang Kastor dan roda - Persyaratan kastor untuk tempat tidur rumah sakit.

4. SNI 09-4663-1998 juga dianggap terlalu umum sehingga apabila diterapkan maka mutu produk kurang terukur.

5. Kalimat yang digunakan pada parameter memiliki arti yang kurang jelas, yaitu: a) Kursi roda pada keadaan terbuka harus menempel pada lantai dan b) Posisi kursi roda minimal tegak lurus dari lantai dan tidak boleh miring kearah sudut negatif (keluar).

Hambatan penerapan SNI 09-46631998 antara lain: 
1. Penerapan standar akan mengakibatkan kenaikan biaya produksi yang berakibat meningkatnya harga jual. Sedangkan kursi roda impor memiliki harga yang lebih murah hingga $50 \%$.

2. Lembaga Penilaian Kesesuaian dengan ruang lingkup kursi roda belum tersedia.

3. Pengawasan produk kursi roda dilakukan secara post border oleh Kementerian Kesehatan sehingga produk impor yang tidak memenuhi standar telah beredar dipasaran.

4. Kementerian Kesehatan selaku regulator tidak menjadikan SNI 09-4663-1998 sebagai acuan penilaian dan persyaratan izin edar.

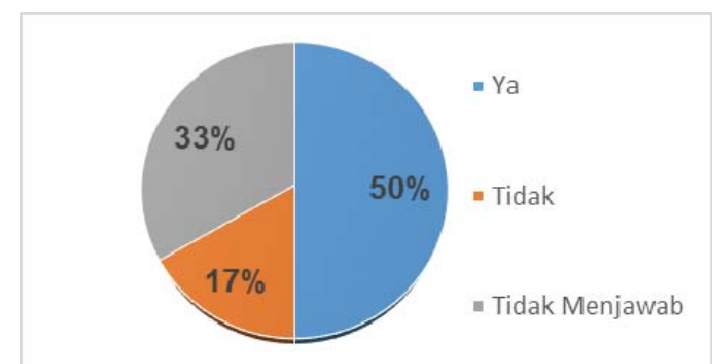

Gambar 2 SNI 09-4663-1998 diterapkan wajib.

Meskipun terdapat permasalahan dalam penerapan SNI-nya, $50 \%$ produsen kursi roda (responden) setuju SNI 09-4663-1998 diberlakukan secara wajib (Gambar 2), dengan pertimbangan diperlukan komitmen dari Kementerian Kesehatan, pembinaan perusahaan apabila belum mampu memenuhi standar, penyiapan Lembaga Penilaian Kesesuaian. Responden juga menyetujui adanya pengkajian ulang SNI 09-4663-1998.

\section{KESIMPULAN}

Berdasarkan hasil penelitian, SNI 09-46631998 belum diterapkan secara maksimal oleh produsen, hanya 33,33\% (2 dari 6 responden). Hal ini dikarenakan regulator belum menjadikan SNI 09-4663-1998 sebagai dasar penilaian dan persyaratan izin edar produk kursi roda, serta SNI belum dapat memenuhi kebutuhan pasar. Sebanyak $66,67 \%$ (4 dari 6 responden) menggunakan standar ISO 7176 series, hal ini dikarenakan $33,33 \%$ produsen telah melakukan ekspor.

SNI 09-4663-1998 dianggap tidak mengikuti perkembangan teknologi terkini dan standar internasional yang berlaku ISO 7176 series, yaitu hanya memuat aspek kekuatan dan sifat tampak. Diperlukan revisi SNI 094663-1998 yang minimal mencakup parameter keamanan, kekuatan dan ketahanan. Penerapan standar di Indonesia harus dibarengi dengan kesiapan Lembaga Penilaian Kesesuaian. Selanjutnya selaras dengan berlakunya Undang-Undang Nomor 36 Tahun 2009, Kementerian Kesehatan sebaiknya mempertimbangkan penerapan SNI secara wajib sebagai persyaratan izin edar produk kursi roda.

\section{UCAPAN TERIMA KASIH}

Ucapan terima kasih kami sampaikan kepada Pusat Riset dan Pengembangan Sumber Daya Manusia (Pusrisbang SDM) - Badan Standardisasi Nasional yang telah membiayai penelitian ini melalui APBN Tahun 2018. Karya Tulis IImiah ini merupakah salah satu luaran penelitian kerjasama antara Pusrisbang SDM dengan Universitas Sebelas Maret Surakarta.

\section{DAFTAR PUSTAKA}

Ady, W. (2011). Pengembangan desain kursi roda khususnya pada lansia berdasarkan citra (image) produk dengan metode kansei engineering. Surakarta. Retrieved from http://eprints.uns.ac.id/3531/

Arikunto. (2010). Prosedur Penelitian: Suatu Pendekatan Praktek. Jakarta: Rineka Cipta.

Badan Standardisasi Nasional. (1998). SNI 094663-1998 Kursi roda.

Frost, K. L., Bertocci, G., Stillman, M. D., Smalley, C., \& Williams, S. (2015). Accessibility of outpatient healthcare providers for wheelchair users: Pilot study. Journal of Rehabilitation Research and Development, 52(6), 653-662.

Gebrosky, B., Pearlman, J., Cooper, R. A., Cooper, R., \& Kelleher, A. (2013). Evaluation of lightweight wheelchairs using ANSI/RESNA testing standards. Journal of Rehabilitation Research and Development, 50(10), 1373-1390. https://doi.org/10.1682/JRRD.2012.08.01 55

Batan, I Made Londen. (2006). Pengembangan Kursi Roda Sebagai Upaya Peningkatan Ruang Gerak Penderita Cacat Kaki. Jurnal Teknik Industri, 8(2), 97-105.

International Organization for Standardization. (2008). ISO 7176-4 Wheelchair: Energy consumption of electric wheelchairs and scooters for determination of theoretical distance range (Vol. 2008). Switzerland: ISO.

International Organization for Standardization. (2014). ISO 7176-8 Wheelchair: Requirements and test methods for 
static, impact and fatigue strengths. Switzerland: ISO.

International Organization for Standardization. (2015). ISO 7176-28 Wheelchairs: Requirements and test methods for stairclimbing devices (Vol. 2012). ISO.

International Organization for Standardization. (2017). ISO 7176-2 Wheelchair: Determination of dynamic stability of electrically powered wheelchairs (Vol. 2006). Switzerland: ISO.

Mhatre, A., Ott, J., \& Pearlman, J. (2017). Development of wheelchair caster testing equipment and preliminary testing of caster models. African Journal of Disability, $\quad 6, \quad 1-16$. https://doi.org/10.4102/ajod.v6i0.358

Pradita, A. A., Priadythama, I., \& Susmartini, S. (2018). Perancangan Ulang Kursi Roda Manual Menggunakan Kriteria Standar ISO 7176-5. PERFORMA: Media IImiah Teknik Industri, 17(1), 54-60. https://doi.org/10.20961/performa.17.1.1 9068

Pratiwi, R. A., Fahma, F., Sutopo, W., \& Pujiyanto, E. (2018). Usulan Kerangka Standar Kursi Roda Manual Sebagai Acuan Penyusunan Standar Nasional Indonesia ( SNI ). Jurnal Standardisasi, 20(3), 207-217.
Pratiwi, R. A., Fahma, F., Sutopo, W., Pujiyanto, E., Suprapto, \& Ayundyahrini, M. (2018). Designing Parameter for Developing Standard of Manual Wheelchair. International Journal of Applied Science and Engineering, 15(2), 127-134.

https://doi.org/10.6703/IJASE.201810

Sahl, A., Sufa, M. F., \& Nursanti, I. (2014). Perancangan Alat Bantu Kursi Roda Magnetis Dengan Metode QFD (Quality Function Deployment). Jurnal IImiah Teknik Industri (Vol. 8).

Soewardi, H., Ajie, B. T., \& Jalal, R. A. (2015). Inovative Design Of Wheelchair By Using User Centered Design Approach No Atribut Forceful Multifunction Flexible Ergonomics. In Proceeding 8th International Seminar on Industrial Engineering and Management (pp. 8186).

Tarsidi, D. (2011). Kendala Umum yang Dihadapi Penyandang Disabilitas dalam Mengakses Layanan Publik. Jurnal Asesmen Dan Intervensi Anak Berkebutuhan Khusus, 10(2), 201-205.

Thohari, S. (2014). Pandangan Disabilitas dan Aksesibilitas Fasilitas Publik bagi Penyandang Disabilitas di Kota Malang. ljds, $\quad 1(1), \quad 27-37$. https://doi.org/10.1016/j.measurement.20 14.09.078 